\title{
Inhibition of JAK2 attenuates the increase in inflammatory markers in microglia from APP/PS1 mice
}

\author{
Raasay S. Jones, Aedín M. Minogue, Orla Fitzpatrick, Marina A. Lynch* \\ Trinity College Institute of Neuroscience, Trinity College, Dublin, Ireland
}

\section{A R T I C L E I N F O}

\section{Article history:}

Received 2 February 2015

Received in revised form 27 April 2015

Accepted 29 April 2015

\section{Keywords:}

JAK2

$\mathrm{M} 1 / \mathrm{M} 2$

TG101209

Microglia

APP/PS1

\begin{abstract}
A B S T R A C T
There is a wealth of evidence indicating that macrophages adopt distinct phenotypes when exposed to specific stimuli and, in the past few years, accumulating data suggest that microglia behave somewhat similarly. Therefore, microglia can adopt the so-called M1 or M2 phenotypes in response to interferon- $\gamma$ (IFN $\gamma$ ) and interleukin-4, respectively. Although it has yet to be unequivocally proven in the context of microglia, acutely activated M1 cells are probably protective, although a persistent M1 state is likely to be damaging, whereas M2 cells may be reparative and restorative. In this case, particularly because the current evidence suggests the development of a predominantly M1 state with age and in neurodegenerative diseases, it is important to identify mechanisms by which polarization of microglia can be modulated. The present findings indicate that exposure of cultured microglia to IFN $\gamma$ increased expressions of the archetypal markers of the M1 phenotype, tumour necrosis factor- $\alpha$, and inducible nitric oxide synthase, and preexposure of cells to amyloid- $\beta(A \beta)$ sensitized microglia to subsequent stimulation with IFN $\gamma$. Importantly, this synergy was also evident in microglia prepared from the brains of transgenic mice that overexpress amyloid precursor protein (APP) and presenilin 1 (PS1, APP/PS1 mice) and are exposed to a combination of increasing concentrations of endogenous $A \beta$ from 4 or 5 months of age and an age-related increase in IFN $\gamma$. Significantly, the JAK2 inhibitor, TG101209, attenuated the IFN $\gamma$ induced changes in cultured microglia and in isolated microglia prepared from APP/PS1 mice. These findings suggest that targeting JAK2 may be a potential strategy for reducing neuroinflammation in Alzheimer's disease.
\end{abstract}

(c) 2015 Elsevier Inc. All rights reserved.

\section{Introduction}

Over 2 decades ago, it was reported that macrophages respond to stimuli by adopting different phenotypes (Stein et al., 1992). The so-called classically activated macrophages were identified by upregulation of tumour necrosis factor $\alpha$ (TNF $\alpha$ ) messenger RNA (mRNA) and nitric oxide synthase (NOS)2 mRNA; this phenotype, also called the M1 phenotype, is induced by interferon- $\gamma($ IFN $\gamma)$ and Toll-like receptor agonists such as lipopolysaccharide; however, it is now accepted that a number of other factors can give rise to an M1like phenotype (Martinez and Gordon, 2014). In vivo, M1 macrophages are induced in response to exposure of tissue to infection and have a protective function. An alternatively activated M2 phenotype is triggered by anti-inflammatory cytokines such as interleukin (IL)-4, and these cells have been shown to play a role in tissue repair (Gordon and Martinez, 2010; Stein et al., 1992).

\footnotetext{
* Corresponding author at: Trinity College Institute of Neuroscience, Trinity College, Dublin, Ireland. Tel.: +3531 8968531; fax: +35318963545.

E-mail address: lynchma@tcd.ie (M.A. Lynch).
}

Interestingly, M2 cells are considered to be more phagocytic than M1 cells (Cherry et al., 2014).

In the past 5 or 6 years, it has become clear that microglia also respond differently to IFN $\gamma$ and IL- 4 and, at least to some extent, express molecules indicative of the M1 and M2 phenotypes identified in macrophages (Chhor et al., 2013; Colton and Wilcock, 2010). Recent evidence has suggested that M1 microglia predominate in the brains of aged animals and transgenic mice that overexpress amyloid precursor protein (APP) and presenilin 1 (PS1, APP/ PS1 mice, Minogue et al., 2014), a commonly used mouse model of Alzheimer's disease (AD), and in CD200-deficient mice in which inflammatory changes have been described (Denieffe et al., 2013). It is generally agreed that cells in the brain produce little, if any, IFN $\gamma$, and previous findings from this laboratory have suggested that the source of the cytokine in aged, CD200-deficient, and APP/PS1 mice is infiltrating IFN $\gamma^{+} \mathrm{T}$ cells, macrophages and natural killer cells (Denieffe et al., 2013; Kelly et al., 2013; McManus et al., 2014; Minogue et al., 2014). These cells are able to infiltrate not only because of an increased production of chemokines, such as monocyte chemoattractant protein (MCP)-1, but also because of 
enhanced permeability of the blood-brain barrier (Denieffe et al., 2013; Kelly et al., 2013; Minogue et al., 2014).

IFN $\gamma$ is the sole type II IFN and it signals through the IFN $\gamma$ receptor (IFN $\gamma \mathrm{R})$. Once the IFN $\gamma \mathrm{R}$ is ligated, it induces its effects through JAK 1 and 2 that heterodimerize and phosphorylate leading to recruitment of signal transducer and activator of transcription (STAT)1, which homodimerizes and translocates to the nucleus where it modulates expression of IFN $\gamma$-responsive genes (Kotenko and Pestka, 2000). There are more than 200 genes that IFN $\gamma$ can regulate, and these include the archetypal markers of M1 cells, $\mathrm{TNF} \alpha$, and inducible NOS (iNOS) and other inflammatory cytokines such as IL-6 and IL-1 $\beta$ (Boehm et al., 1997). Interestingly, in APP/PS1 mice, we observed an age- and genotype-related increase in IFN $\gamma \mathrm{R}$ expression on $\mathrm{CD}_{11} \mathrm{~b}^{+}$cells, and this was accompanied by increased IFN $\gamma$ concentration and increased STAT1 activation in hippocampus (Minogue et al., 2014). In contrast, no change in expression of mannose receptor 1 (MRC1) mRNA, a marker of M2 activation, was observed in parallel with an age-related decrease in CD11b ${ }^{+} \mathrm{IL}-4 \mathrm{R}^{+}$ cells. This persistent M1 polarization is probably a key to the agerelated neuroinflammation in APP/PS1 mice, and the evidence has indicated that M1 microglia are present in the postmortem brain of AD patients, although M2 cells are also present (Colton et al., 2006).

We set out to assess whether preexposure of microglia to amyloid- $\beta(A \beta)$ modulated the responsiveness of the cells to IFN $\gamma$. Therefore, we assessed the effect of incubating microglia cultured from neonatal mice in the presence of $A \beta$ and IFN $\gamma$ and the effect of incubating microglia isolated from APP/PS1 mice to IFN $\gamma$. We demonstrate that IFN $\gamma$ and $A \beta$ upregulate markers of inflammation and show that the JAK2 inhibitor, TG101209, effectively attenuates the IFN $\gamma$-induced changes in microglia.

\section{Materials and methods}

\subsection{Animals}

Groups of 12- to 14-month-old ( $n=4)$ APPswe/PS1dE9 (APP/PS1) mice and wild-type (WT) littermate controls were used in this study. Mice, initially purchased from The Jackson Laboratory (USA), were bred with C57BL/6 animals in a specific pathogen-free environment at the BioResources Unit of Trinity College, Dublin. All experimental work was performed under a licence granted by the Minister for Health and Children (Ireland) under the Cruelty to Animals Act 1876 and the European Community Directive 86/609/EEC.

\subsection{Preparation and treatment of primary microglial cell cultures}

Primary microglia were prepared from brains of 1-day-old neonatal mice (Bioresources Unit, Trinity College, Dublin, Ireland) as described previously (Jones et al., 2013). The meninges and adherent blood vessels were removed, and cortical tissue was dissected, cross-chopped, and incubated (20 minutes and $37^{\circ} \mathrm{C}$ ) in Dulbecco-modified Eagle medium (DMEM; Invitrogen, UK) supplemented with $10 \%$ fetal bovine serum (FBS) and $50 \mathrm{U} / \mathrm{mL}$ penicillin/streptomycin (Invitrogen). Tissue was triturated, passed through a nylon cell strainer $(40 \mu \mathrm{M})$, and centrifuged $(800 \times g$, 3 minutes, and $20^{\circ} \mathrm{C}$ ). To prepare purified microglial cultures, cells were seeded onto T25 flasks, and after 24 hours, media was replaced with DMEM containing macrophage colony-stimulating factor (10 ng/mL; R\&D Systems, UK) and granulocyte-macrophage colony-stimulating factor ( $10 \mathrm{ng} / \mathrm{mL}$; R\&D Systems). After 8-9 days, flasks were shaken ( 2 hours, $130 \mathrm{rpm}$, and $37^{\circ} \mathrm{C}$ ) and tapped several times to remove nonadherent microglia. Supernatants were centrifuged $\left(800 \times \mathrm{g}, 3\right.$ minutes, and $\left.20^{\circ} \mathrm{C}\right)$, and the resultant pellet was resuspended in DMEM. Cells were counted, plated onto 24well plates (density: $1 \times 10^{5}$ cells per well), and maintained at 37
${ }^{\circ} \mathrm{C}$ in a $5 \% \mathrm{CO}_{2}$ humidified atmosphere for 2 days before treatment. Fluorescence-activated cell sorting (FACS) analysis revealed that these cells were approximately $80 \%-90 \%$ CD $11 b^{+}$.

\subsection{Isolation of microglia from adult mice}

Microglia were prepared from adult mice using a previously described method (Minogue et al., 2014). Stock isotonic Percoll was obtained by mixing 9 volumes of Percoll (Sigma-Aldrich, UK) with 1 volume of $10 \times$ phosphate-buffered saline (PBS). Further Percoll gradients were prepared with $1 \times$ PBS as appropriate. After sacrifice, brain tissue was dissected and placed in $1 \times$ HBSS (Invitrogen), crosschopped, homogenized, and triturated using fire-polished Pasteur pipettes with 3 decreasing diameters. Cell suspensions were filtered through a cell strainer $(70 \mu \mathrm{M})$, and cells were pelleted by centrifugation. The resultant pellets were resuspended in $75 \%$ Percoll $(10 \mathrm{~mL})$, overlaid with $25 \%$ Percoll $(10 \mathrm{~mL})$ and $1 \times$ PBS $(6 \mathrm{~mL})$, and centrifuged at $800 \times \mathrm{g}$ for 30 minutes at $4{ }^{\circ} \mathrm{C}$. After centrifugation, an enriched microglial population was collected from the $25 \%-75 \%$ interface. Cells were removed, washed, and resuspended in RPMI (Invitrogen) before addition of IFN $\gamma(50 \mathrm{ng} / \mathrm{mL})$ or TG101209 $(2 \mu \mathrm{M})$. FACS analysis revealed that these cells were $60 \%-70 \% \mathrm{CD} 11 \mathrm{~b}^{+}$. The procedure for preparation of cells took approximately 60 minutes, and they were treated immediately after the final resuspension. The concentration of IFN $\gamma$ used in this study was chosen as previous work from this laboratory had indicated a differential response of microglia from WT and APP/PS1 to this concentration (Minogue et al., 2014).

\subsection{Cell treatments}

Primary microglial cultures were incubated with aggregated $A \beta$ $\left(10 \mu \mathrm{M}, 4.2 \mu \mathrm{M} A \beta 1-40\right.$, and $\left.5.8 \mu \mathrm{M} \mathrm{A} \beta_{1-42}\right)$ for 24 hours before coincubation with IFN $\gamma(50 \mathrm{ng} / \mathrm{mL})$ for a further 6 hours. Lyophilized $A \beta_{1-40}$ and $A \beta_{1-42}$ peptides (Invitrogen) were dissolved in high-performance liquid chromatography grade water to provide a 6-mg/mL stock solution, diluted to $1 \mathrm{mg} / \mathrm{mL}$ using sterile PBS and allowed to aggregate ( 24 hours, $220 \mathrm{rpm}$, and $37^{\circ} \mathrm{C}$ ). This preparation contains both oligomers and fibrils as evidenced by enhanced Thioflavin T binding (data not shown). The concentration of IFN $\gamma$ used in this study was chosen as previous work from this laboratory indicated that this concentration reliably and reproducibly induced M1 activation in primary microglia.

To assess the effect of $A \beta$ on cell surface expression of IFN $\gamma R$, primary microglia or a microglial cell line (BV2) were incubated with aggregated $A \beta$ for 24 hours after which cells were harvested for flow cytometric (FACS) analysis.

After treatment, supernatants were collected for enzyme-linked immunosorbent assay (ELISA), and cells were harvested for mRNA analysis. To assess the impact of JAK2 inhibition on IFN $\gamma$-induced changes, primary microglial cultures or microglia isolated from brain tissue of WT and APP/PS1 mice were pretreated with TG101209 ( $2 \mu \mathrm{M}$; Cambridge Bioscience, UK) for 30 minutes before incubation with IFN $\gamma(50 \mathrm{ng} / \mathrm{mL})$ for 1 hour. Cells were harvested for assessment of phospho-STAT1 expression by Western blotting. For analysis of changes in IFN $\gamma$-induced mRNA expression, cells were pretreated with TG101209 ( $2 \mu \mathrm{M}$; Cambridge Bioscience) for 30 minutes before incubation with IFN $\gamma(50 \mathrm{ng} / \mathrm{mL})$ for 6 hours in the case of primary microglial cells and 3 hours in the case of microglia isolated from brain tissue of WT and APP/PS1 mice.

\subsection{Analysis of mRNA expression by real-time polymerase chain reaction}

RNA was isolated from microglial cells using a Nucleospin RNAII kit (Macherey-Nagel GmbH, Germany) and reverse transcribed into 
complementary DNA (cDNA) using a High-Capacity cDNA Archive kit (Applied Biosystems, UK) as per manufacturer's instructions. Equal concentrations of cDNA were used for reverse-transcriptase polymerase chain reaction (PCR) amplification. Real-time PCR primers were delivered as "Taqman Gene Expression Assays" containing forward and reverse primers and a FAM-labeled MGB Taqman probe for each gene (Applied Biosystems). Assay IDs for the genes examined were as follows: $\beta$-actin $(4352341 \mathrm{E})$, arginase-1 (Arg-1, Mm00475988_m1), IL-1 $\beta$ (Mm00434228_m1), IL-6 (Mm00446190_m1), iNOS (Mm00440502_m1), MRC1 (Mm00485148_m1), and TNFa (Mm00443258_m1). We also assessed expressions of cluster of differentiation (CD)40 (Mm00441891_m1) and major histocompatibility complex II (MHCII) (Mm00482914_m1) because they are involved in antigen presentation and are associated with the M1 phenotype and MCP-1 (Mm00441242_m1) because of its chemotactic properties, specifically in the context of its potential to facilitate macrophage infiltration into the brain that occurs with age and in APP/PS1 mice (Denieffe et al., 2013; Kelly et al., 2013; Minogue et al., 2014). Realtime PCR was performed using an ABI Prism 7300 instrument (Applied Biosystems) with $\beta$-actin used as the endogenous control. Relative gene expression was calculated using the $\Delta \Delta C T$ method with Applied Biosystems RQ software (Applied Biosystems).

\subsection{Analysis of cytokine and chemokine concentrations by ELISA}

Supernatant concentrations of IL-6, MCP-1, and TNF $\alpha$ (R\&D Systems, USA) obtained from microglia were measured using ELISA. Briefly, standards or samples $(100 \mu \mathrm{L})$ were added to antibodycoated 96-well plates and incubated for 2 hours at room temperature, plates were washed, and samples were incubated in detection antibody for 2 hours. Plates were washed and incubated in horseradish peroxidase-conjugated streptavidin (1:200 in PBS containing $1 \%$ BSA) for 20 minutes at room temperature. Substrate solution (tetramethylbenzidine; Sigma, UK) was added, incubation continued at room temperature in the dark for 30 minutes, and the reaction was stopped using $1 \mathrm{M} \mathrm{H}_{2} \mathrm{SO}_{4}$. Absorbance measurements were read at $450 \mathrm{~nm}$ using a microplate reader (BioTek Instruments, USA). Concentrations were calculated relative to the appropriate standard curve.

\subsection{Analysis of IFN $\gamma R$ by flow cytometry}

IFN $\gamma$ R expression on microglia or BV-2 cells was assessed by flow cytometry. Briefly, cells were washed with FACS buffer (2\% FBS and $0.1 \% \mathrm{NaN}_{3}$ in PBS), centrifuged (1200 rpm and 5 minutes), resuspended in blocking solution (50\% FBS in FACS buffer) for 30 minutes, centrifuged (1200 rpm and 5 minutes), and resuspended in FACS buffer with Alexa Fluor 647 anti-mouse CD11b (1:100; Serotec, UK) or fluorescein isothiocyanate anti-mouse CD119 $\left(\right.$ IFN $\left.\gamma R^{+}\right)\left(1: 100\right.$; Biosciences) for 30 minutes to identify CD11b ${ }^{+}$ IFN $\gamma \mathrm{R}^{+}$microglia. Unstained cells and fluorescence minus one tubes were used to gate the percentage of positive cells in any channel. Compensation beads were used to optimize fluorescence settings for multicolour flow cytometric analyses. IFN $\gamma \mathrm{R}^{+}$cells were represented as the number of $\mathrm{CD}_{11} \mathrm{~b}^{+}$positive in the fluorescein isothiocyanate channel.

\subsection{Analysis of proteins by Western immunoblotting}

Cells were harvested and homogenized in buffer containing Tris$\mathrm{HCl}(0.01 \mathrm{M})$ and EDTA $(1 \mathrm{mM})$, and protein $(20 \mu \mathrm{g})$ was boiled in gel-loading buffer and separated by $7 \%$ sodium dodecyl sulphatepolyacrylamide gel electrophoresis. Proteins were transferred to nitrocellulose membranes and incubated with antibodies diluted in
$5 \%$ nonfat dried milk in tris-buffered saline containing $0.05 \%$ Tween20. Primary antibodies against phosphorylated STAT1 (1:1000; Cell Signaling Technology, USA) and $\beta$-actin (1:5000; Sigma-Aldrich) were used with horseradish peroxidase-conjugated secondary antibodies (1:10,000; Jackson ImmunoResearch, UK). Bands were visualized using WesternBright ECL (Advansta, USA), and images were captured using a Fujifilm LAS-3000 (Brennan \& Co., Ireland).

\subsection{Statistical analysis}

Data were analyzed using a 2- or 3-way analysis of variance (ANOVA) as appropriate, followed by a Newman-Keul post hoc or a Student $t$-test for independent means to determine which conditions were significantly different from each other. Data are expressed as means + standard error of the mean.

\section{Results}

To investigate the potential synergism between IFN $\gamma$ and $A \beta$, microglial cells were preincubated with $A \beta$ for 24 hours after which time IFN $\gamma$ was added and incubation continued for 6 hours. IFN $\gamma$ significantly increased mRNA expressions of TNF $\alpha$, IL-1 $\beta$, and iNOS $\left({ }^{* *} p<0.01\right.$, 2-way ANOVA, Fig. 1A, B, and D, respectively), and IFN $\gamma$ and $A \beta$ acted synergistically to further increase expression of these molecules $\left({ }^{++} p<0.01\right.$, 2-way ANOVA, IFN $\gamma$ alone vs. IFN $\gamma+\mathrm{A} \beta$, Fig. 1A, B, and D). Similarly, IFN $\gamma$ increased supernatant concentration of TNF $\alpha\left({ }^{* *} p<0.01\right.$, 2-way ANOVA, Fig. 1C) and acted synergistically with $A \beta$ to further enhance its release from microglial cells $\left({ }^{++} p<0.01,2\right.$-way ANOVA, IFN $\gamma$ alone vs. IFN $\left.\gamma+A \beta\right)$. Neither IFN $\gamma$ nor $A \beta$ altered IL- 6 mRNA or supernatant concentration of IL- 6 (Fig. 1E and F) but significantly increased IL-6 mRNA in combination $\left({ }^{++} p<0.01,2\right.$-way ANOVA, IFN $\gamma$ alone vs. IFN $\gamma+A \beta$, Fig. 1E). When the effect of $A \beta$ was assessed separately, we found that it significantly increased TNF $\alpha$ mRNA and supernatant concentration of TNF $\alpha\left({ }^{* *} p<0.01\right.$ and ${ }^{* * *} p<0.001$, respectively, Student $t$-test for independent means).

Both CD40 and MHCII are molecules involved in antigen presentation that have been shown to be associated with the M1 state. Expressions of CD40 and MHCII mRNA were significantly increased in IFN $\gamma$-incubated cells $\left({ }^{* *} p<0.01,{ }^{* * *} p<0.001,2\right.$-way ANOVA, Fig. $1 \mathrm{G}$ and $\mathrm{H}$ ); however, the synergism between IFN $\gamma$ and $A \beta$ was observed only in the case of CD40 $\left({ }^{++} p<0.01,2\right.$-way ANOVA, IFN $\gamma$ alone vs. IFN $\gamma+A \beta$, Fig. $1 \mathrm{H}) ; A \beta$ alone also increased CD40 mRNA ( $p$ $<0.05$, Student $t$-test for independent means). A similar synergism between IFN $\gamma$ and $A \beta$ was observed with MCP- 1 mRNA (data not shown). We also investigated the effect of IFN $\gamma$ and $A \beta$ alone, and in combination, on the expressions of Arg-1 and MRC1, which are markers of the M2 phenotype. Whereas both significantly decreased expression of Arg-1 mRNA, neither affected MRC1 mRNA, and there was no evidence of a synergism between IFN $\gamma$ and $A \beta$ (data not shown).

We considered that IFN $\gamma$ and $A \beta$ might similarly synergize in vivo, specifically in APP/PS1 mice in which there is an endogenous progressive increase in $A \beta$ with age. To assess this, we prepared microglia from 12- to 14-month-old WT and APP/PS1 mice and incubated them in the presence of IFN $\gamma$. IFN $\gamma$ significantly increased mRNA expressions of TNF $\alpha$, iNOS, CD40, and MHCII in microglia prepared from WT and APP/PS1 mice $\left({ }^{* *} p<0.01,{ }^{* * *} p<\right.$ 0.001, 2-way ANOVA, Fig. 2A, B, C, and D, respectively); however, the effect of IFN $\gamma$ was markedly enhanced in microglia prepared from APP/PS1, compared with WT mice $\left(^{++} p<0.01,2\right.$-way ANOVA, IFN $\gamma$ alone vs. IFN $\gamma+A \beta$, Fig. $2 A-D)$. This suggests that the synergism between IFN $\gamma$ and $A \beta$ is also evident in vivo. In an effort to understand how this may occur, a microglial cell line (BV2) was exposed to $A \beta$ for 24 hours, and the expression of IFN $\gamma R$ on the 

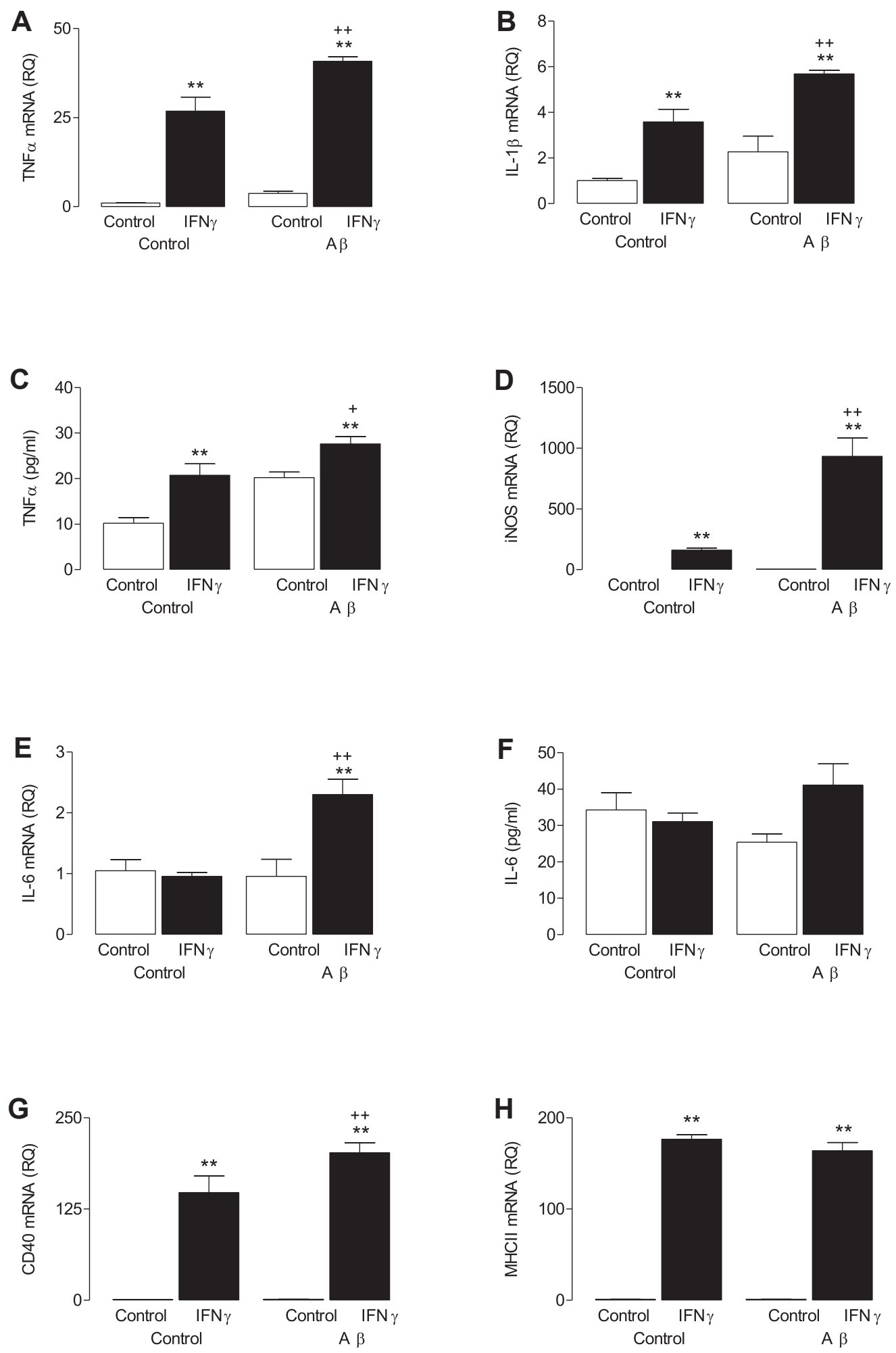

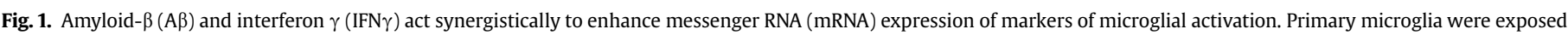

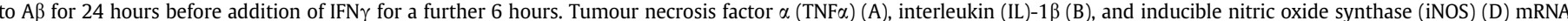

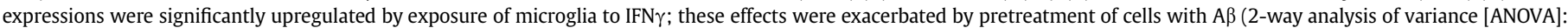

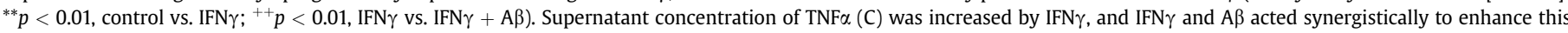

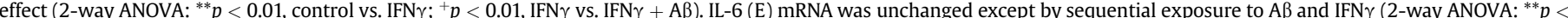

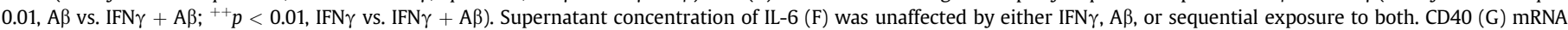

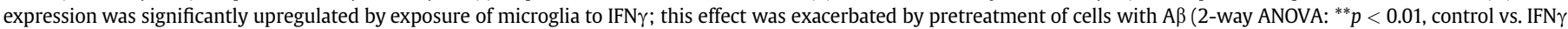

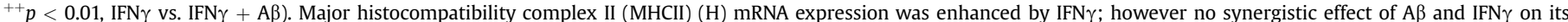

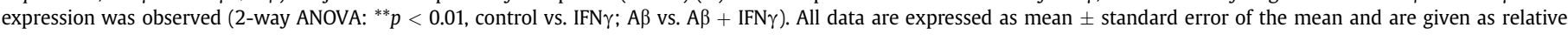
quantities (RQ) 
surface of the cells was assessed by flow cytometry. Flow cytometric analysis revealed an $A \beta$-induced upregulation in surface expression of IFN $\gamma \mathrm{R}$ on microglial cells $\left({ }^{* * *} p<0.001\right.$, Student $t$-test for independent means, Fig. 2E). This effect was also observed in primary neonatal microglia $\left({ }^{*} p<0.05\right.$, Student $t$-test for independent means, Fig. 2E).

IFN $\gamma$ induces STAT1 phosphorylation that dimerizes and translocates to the nucleus to upregulate the transcription of proinflammatory cytokines. We assessed the effect of modulating activation of the upstream JAK2 on the IFN $\gamma$-induced changes using the specific JAK2 inhibitor TG101209 in cultured microglia prepared from neonatal mice. Predictably, IFN $\gamma$ increased the expression of phosphorylated STAT1 $\left({ }^{*} p<0.05,2\right.$-way ANOVA, Fig. 3A and B), and this was inhibited when cells were pretreated with TG101209 $\left({ }^{++} p\right.$ $<0.01,2$-way ANOVA, IFN $\gamma$ alone vs. IFN $\gamma+$ TG101209, Fig. 3A and B). As before, IFN $\gamma$ significantly increased mRNA expressions of TNF $\alpha$, iNOS, IL-1 $\beta$, and IL-6 $\left({ }^{*} p<0.05,{ }^{* *} p<0.01\right.$, ${ }^{* * *} p<0.001$, 2 way ANOVA, Fig. 3C-F), and TG101209 completely blocked the
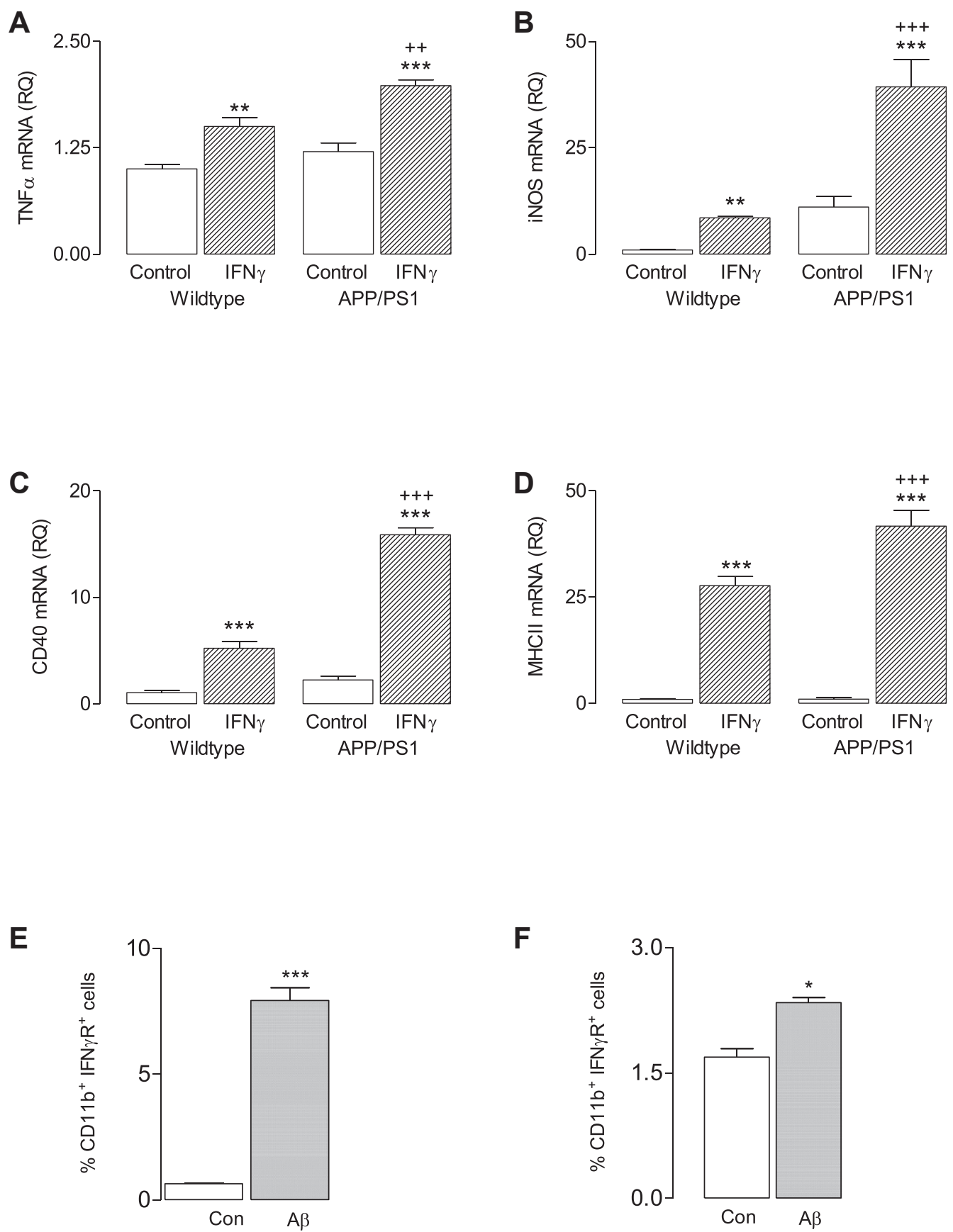

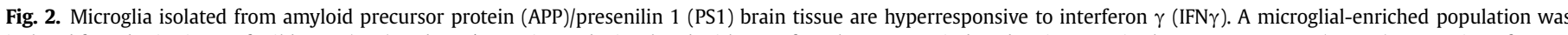

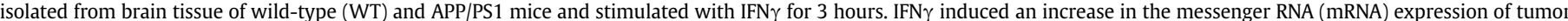

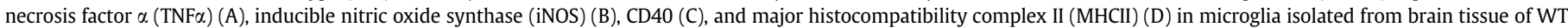

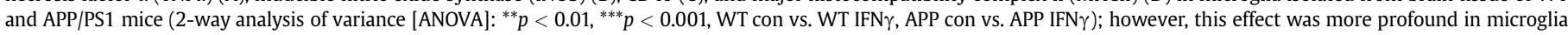

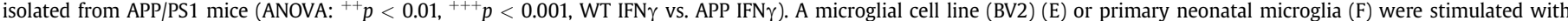

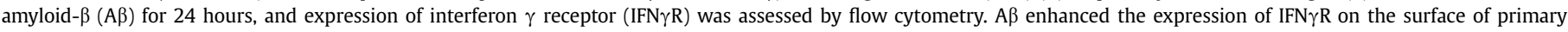
microglia (E) and BV2 (F) cells $\left({ }^{*} p<0.05,{ }^{* * *} p<0.001\right.$, Student $t$ - test for independent means, $n=3$ ). All data are expressed as mean \pm standard error of the mean. 
A
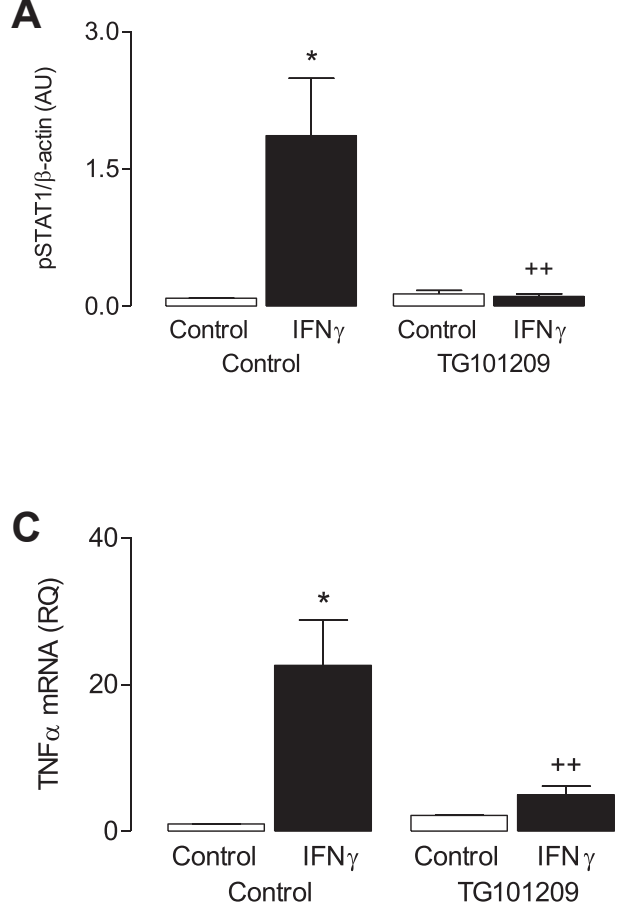

E
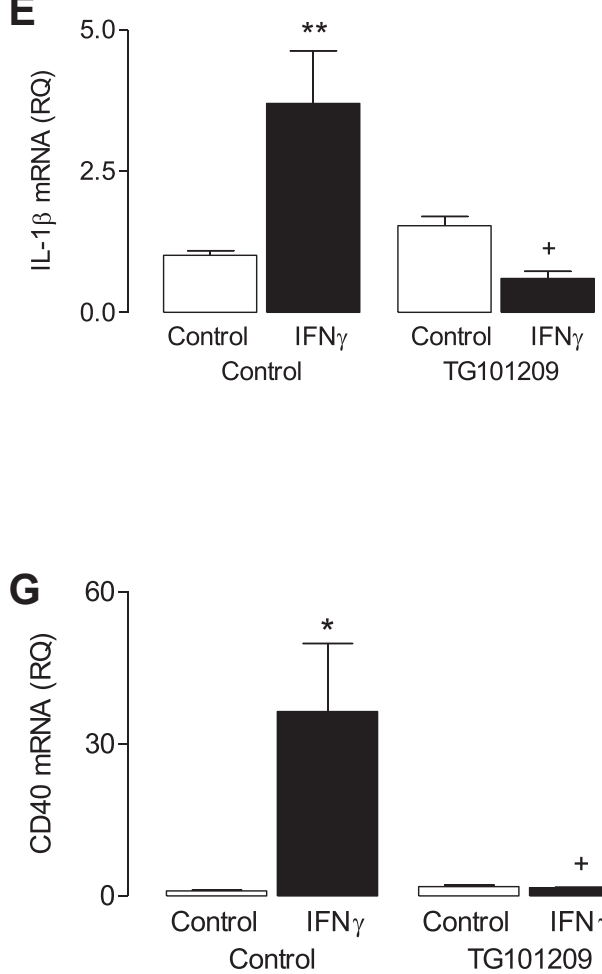

B
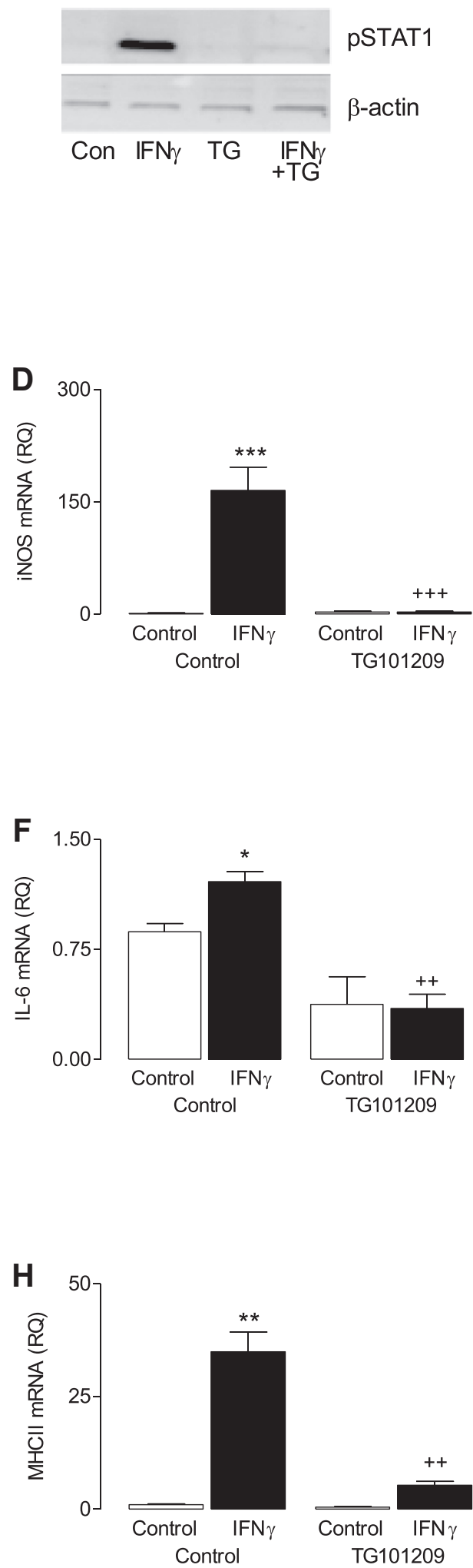

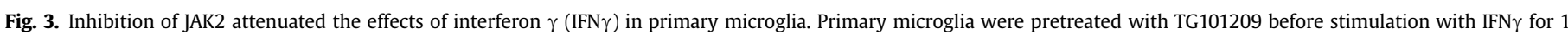

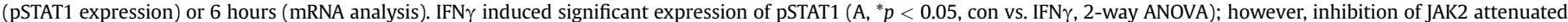

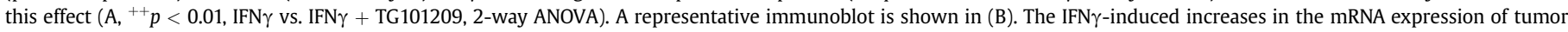

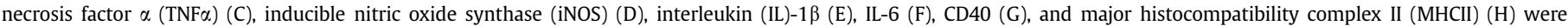

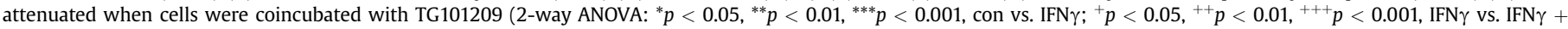
TG101209). Abbreviation: AU, arbitrary units. 
IFN $\gamma$-induced changes $\left({ }^{+} p<0.05,{ }^{++} p<0.01,{ }^{+++} p<0.001,2\right.$-way ANOVA, IFN $\gamma$ alone vs. IFN $\gamma+$ TG101209). Similarly, IFN $\gamma$ significantly increased CD40 and MHCII mRNA in microglia $\left({ }^{*} p<0.05,{ }^{* *} p\right.$ $<0.01,2$-way ANOVA, Fig. 3G and H), and TG101209 completely blocked this effect $\left({ }^{+} p<0.05,{ }^{++} p<0.01,2\right.$-way ANOVA, IFN $\gamma$ alone vs. IFN $\gamma+$ TG101209). TG101209 had no effect on cell viability as assessed by lactate dehydrogenase release (data not shown).

Having established a modulatory effect of TG101209 on the effects of IFN $\gamma$ in cultured microglia, we asked whether such an effect might also be effective in modulating the persistent effects of endogenous $A \beta$ on microglia prepared from APP/PS1 mice. Therefore, isolated microglia from WT and APP/PS1 mice were preincubated with TG101209 for 30 minutes after which time IFN $\gamma$ was added and incubation continued for 3 hours. As mentioned earlier,
IFN $\gamma$ increased TNF $\alpha$ mRNA and iNOS mRNA in cells from WT and APP/PS1 mice $\left({ }^{* *} p<0.01\right.$, 3-way ANOVA, Fig. 4A and B), and again, the effect was enhanced in microglia from APP/PS1 mice $\left({ }^{+} p<0.05\right.$, ${ }^{++} p<0.01$, 3-way ANOVA, IFN $\gamma$ effect in microglia from WT vs. APP/ PS1 mice). TG101209 completely blocked the IFN $\gamma$-induced changes $\left({ }^{\S} p<0.01,3\right.$-way ANOVA). IFN $\gamma$ also increased mRNA expressions of IL-1 $\beta$ and IL-6 in microglia from WT and APP/PS1 mice $\left({ }^{* *} p<\right.$ 0.01, 3-way ANOVA, Fig. 4C and D), and the effect in microglia from APP/PS1 mice was significantly greater in the case of IL- $6\left({ }^{++} p<\right.$ 0.01, 3-way ANOVA, IFN $\gamma$ effect in microglia from WT vs. APP/PS1 mice). TG101209 completely blocked the IFN $\gamma$-induced changes $\left({ }^{\S \S} p<0.01,3\right.$-way ANOVA). Interestingly, there was a genotyperelated increase in IL-1 $\beta$ mRNA $\left({ }^{\# \#} p<0.01\right)$. Expressions of both CD40 and MHCII mRNA were significantly increased in IFN $\gamma$-treated
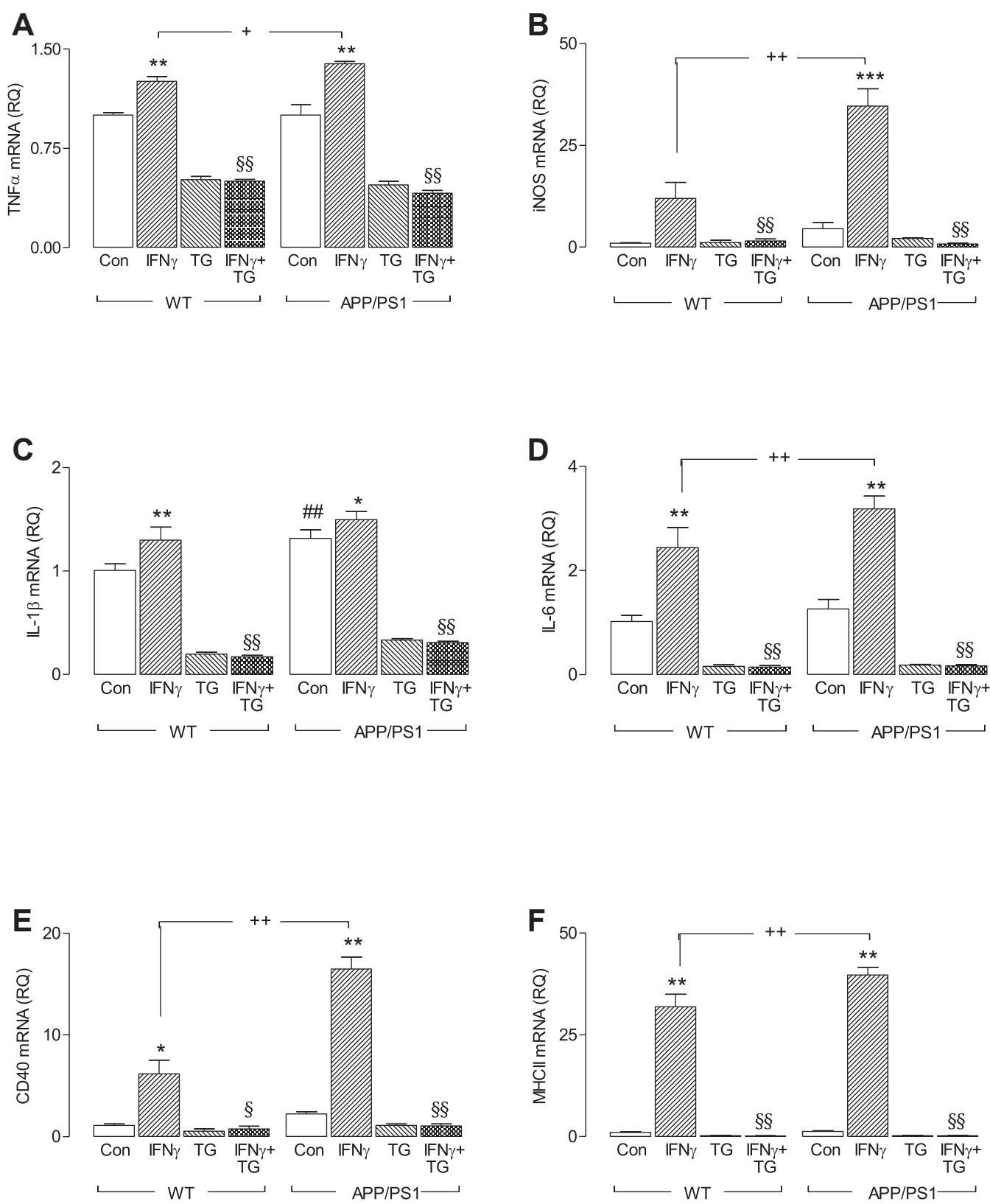

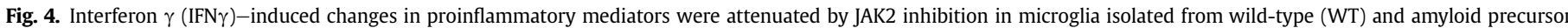

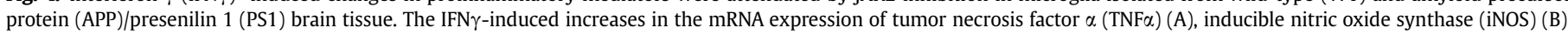

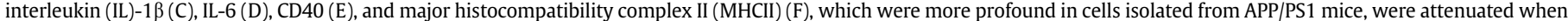

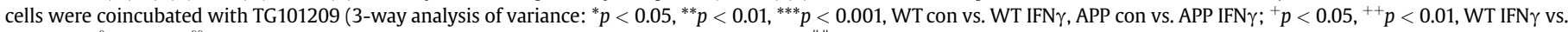
APP IFN $\gamma ;{ }^{\S} p<0.05,{ }^{\S} p<0.01$, WT IFN $\gamma$ vs. WT IFN $\gamma+$ TG, APP IFN $\gamma$ vs. APP IFN $\gamma+$ TG); ${ }^{\sharp \#} p<0.01$. All data are expressed as mean \pm standard error of the mean. 
microglia from WT and APP/PS1 mice $\left({ }^{*} p<0.05,{ }^{* *} p<0.01\right.$, 3-way ANOVA, Fig. 4E and F); however, this effect was enhanced in APP/ PS1 microglia $\left({ }^{++} p<0.01,3\right.$-way ANOVA, IFN $\gamma$ effect in microglia from WT vs. APP/PS1 mice). TG101209 completely blocked the IFN $\gamma$-induced increase in CD40 mRNA and MHCII mRNA ${ }^{\S \S} p<0.01$, 3-way ANOVA). Interestingly, incubation of cells with TG101209 decreased expression of these cytokines less than the baseline levels suggesting some tonic activation of JAK2.

\section{Discussion}

The significant finding of this study is that microglia prepared from APP/PS1 mice express markers that are indicative of M1 activation and that the JAK2 inhibitor, TG101209, decreased expression of these markers. Consistent with the observation that $\mathrm{A} \beta$ and IFN $\gamma$ synergize to increase expressions of TNF $\alpha$ and iNOS in cultured microglia, ex vivo microglia from APP/PS1 mice were more reactive to exogenously applied IFN $\gamma$, an effect that was inhibited by TG101209. The implication of this finding is that targeting JAK2 may modulate the ongoing neuroinflammatory changes that characterize AD.

IFN $\gamma$ predictably increased expression of several inflammatory markers indicative of the M1 activation state in microglia as shown previously (Chhor et al., 2013; Denieffe et al., 2013). A $\beta$ alone exerted a modest effect on TNF $\alpha$ mRNA and protein expression that concurs with the earlier findings (Michelucci et al., 2009). However, the stimulatory effect of $A \beta$ was markedly less than IFN $\gamma$. More interestingly, IFN $\gamma$ acted synergistically with $A \beta$ on cultured microglia to increase mRNA expression of the archetypal markers of the M1 phenotype, TNF $\alpha$ and iNOS, in addition to IL-1 $\beta$ and IL-6. Although, to our knowledge, there are no comparable data, the results resemble the finding that $A \beta_{25}-35$-induced release of TNF $\alpha$, and $\mathrm{NO}_{2}^{-}$was enhanced in a microglial cell line, $\mathrm{N9}$, after exposure to IFN $\gamma$, although an additive rather than synergistic effect was observed in the case of TNF $\alpha$ (Meda et al., 1995). Under the present experimental conditions, the synergism between $A \beta$ and IFN $\gamma$ was also evident in the case of CD40, but not MHCII, mRNA and in the case of MCP-1 mRNA, but not supernatant, expression. One possible mechanism by which $A \beta$ acts to "prime" the cells for subsequent IFN $\gamma$ stimulation is by increasing expression of IFN $\gamma$ receptor, and we have found by flow cytometry that incubation of both primary microglia and BV2 cells with A $\beta$ markedly increased the percentage of $\mathrm{CD} 11 \mathrm{~b}^{+} \mathrm{IFN} \gamma \mathrm{R}^{+}$cells in the cultures. Although IFN $\gamma$ and $A \beta$ both decreased mRNA expression of the M2 marker, Arg-1, there was no evidence of an additive or synergistic effect, and no change in MRC1 mRNA was observed.

We considered that the synergism observed between IFN $\gamma$ and exogenously applied $A \beta$ might extend to a situation where microglia are exposed to endogenous $A \beta$, for example, in APP/PS1 mice. To assess this, we compared the effect of IFN $\gamma$ on microglia from WT and APP/PS1 mice. Consistent with the changes observed with exogenously applied $A \beta$, we report that IFN $\gamma$ exerted a greater effect on mRNA expressions of TNF $\alpha$, iNOS and CD40 and MHCII, in microglia prepared from APP/PS1, compared with WT, mice. An important implication of this finding lies in the fact that $A \beta$ accumulation begins in these mice at 3-4 months of age (Gengler et al., 2010; Jankowsky et al., 2005) and microglia in this environment are, therefore, likely to be primed by $A \beta$ before exposure to an agerelated increase in IFN $\gamma$. Thus, we have found that IFN $\gamma$-producing T cells, macrophages, and natural killer cells infiltrate the brain of APP/PS1 mice (McManus et al., 2014; Minogue et al., 2014), and, although there is little evidence of this in 6-month-old mice, significant infiltration occurs by 12 months of age and beyond (McManus et al., 2014; Minogue et al., 2014). Therefore, the possibility exists that infiltrating cells, on releasing IFN $\gamma$, exert a disproportionate effect on the resident microglia and propagate the existing neuroinflammation. A further relevant finding is that bone marrow-derived macrophages prepared from APP/PS1 mice respond more profoundly to IFN $\gamma$ than cells from WT mice (Barrett et al., 2015), and this raises the possibility that when these cells infiltrate the brain and encounter the inflammatory environment that occurs in APP/PS1 mice, they may further contribute to the inflammation. It is important to recognize that others have reported that macrophages can facilitate $A \beta$ removal and, from this perspective, are protective in models of AD (El Khoury et al., 2007; Rezai-Zadeh et al., 2011; Town et al., 2008), although the phagocytic potential of macrophages has been questioned (Fiala et al., 2005). To date, our studies indicate that infiltration of macrophages is associated with increased $A \beta$ accumulation, particularly in older APP/PS1 mice. It should be emphasized that the infiltration of macrophages is accompanied by other IFN $\gamma$-producing cells, and this, together with the older age of the animals, may suggest that the beneficial effects of macrophages are age dependent.

Several groups have suggested that microglia are primed under certain circumstances (Perry and Holmes, 2014), for example, with age (Godbout et al., 2005) or previous exposure to insult, for example, in mice injected with scrapie-infected brain homogenate to induce murine prion disease (Combrinck et al., 2002) or altered neurotransmitter tone, for instance, acetylcholine (van Gool et al., 2010) and are, therefore, rendered more vulnerable to subsequent inflammatory stimuli. The present findings are consistent with this idea; the synergism between $A \beta$ and IFN $\gamma$ may suggest that exposure of microglia to the increasing concentrations of endogenous $A \beta$ that occur in APP/PS1 mice, and in AD, primes microglia and enhances their subsequent responsiveness to IFN $\gamma$.

It is interesting that only modest genotype-related increases were observed in unstimulated microglia prepared from APP/PS1, compared with WT, mice, and these were observed in some, although not all inflammatory markers. This may indicate that overt changes in microglial activation begin only after 12 months of age. More robust changes were observed when analysis was carried out in brain tissue from animals of the same age (McManus et al., 2014; Minogue et al., 2014) suggesting that other cells, particularly astrocytes, may contribute to upregulation of inflammatory markers.

Because IFN $\gamma$, like several other cytokines, triggers phosphorylation of JAK1 and JAK2 to induce its effects, it is predictable that inhibiting these kinases will block IFN $\gamma$-induced changes. Thus, the JAK1/2 inhibitor, AZD1480, has been shown to inhibit IFN $\gamma$-induced nitrite production in bone marrow-derived macrophages (Liu et al., 2014). It is proposed that this may contribute to its ability to ameliorate disease severity in experimental autoimmune encephalomyelitis (Liu et al., 2014), an animal model of multiple sclerosis, in which a key role for IFN $\gamma$ has been identified (Dungan et al., 2014). Here, we show that the specific JAK2 inhibitor TG101209 completely blocked the effect of IFN $\gamma$ on markers of M1 activation in cultured microglia from neonatal mice; predictably, this was accompanied by an inhibition of IFN $\gamma$-induced STAT1 activation. The more significant finding, however, is that inhibiting JAK2 also effectively blocked the IFN $\gamma$-induced changes in microglia from WT and APP/PS1 mice. Indeed, TG101209 decreased the expression of several inflammatory markers in untreated cells from WT and APP/ PS1 mice, whereas it completely blocked the effect of IFN $\gamma$ on microglia from both WT and APP/PS1 mice. These findings suggest that JAK2 inhibition may be a potential treatment of neuroinflammation, and, in this context, it is relevant that ongoing clinical trials investigating the use of JAK $1 / 2$ inhibitors in the attenuation of inflammation have demonstrated promising results and limited side effects (Kontzias et al., 2012; Pardanani, 2008; Verstovsek et al., 2012). 


\section{Disclosure statement}

The authors have no conflicts of interest to disclose.

\section{Acknowledgements}

This work was funded by Science Foundation Ireland to MAL (11/ PI/1014). RSJ, AMM, and OF contributed equally to this work.

\section{References}

Barrett, J.P., Minogue, A.M., Jones, R.S., Ribeiro, C., Kelly, R.J., Lynch, M.A., 2015. Bone marrow-derived macrophages from AbetaPP/PS1 mice are sensitized to the effects of inflammatory stimuli. J. Alzheimers Dis, 44, 949-962.

Boehm, U., Klamp, T., Groot, M., Howard, J.C., 1997. Cellular responses to interferongamma. Annu. Rev. Immunol. 15, 749-795.

Cherry, J.D., Olschowka, J.A., O'Banion, M.K., 2014. Neuroinflammation and M2 microglia: the good, the bad, and the inflamed. J. Neuroinflammation 11, 98.

Chhor, V., Le Charpentier, T., Lebon, S., Ore, M.V., Celador, I.L., Josserand, J., Degos, V., Jacotot, E., Hagberg, H., Savman, K., Mallard, C., Gressens, P., Fleiss, B., 2013. Characterization of phenotype markers and neuronotoxic potential of polarised primary microglia in vitro. Brain Behav. Immun. 32, 70-85.

Colton, C.A., Mott, R.T., Sharpe, H., Xu, Q., Van Nostrand, W.E., Vitek, M.P., 2006. Expression profiles for macrophage alternative activation genes in $\mathrm{AD}$ and in mouse models of AD. J. Neuroinflammation 3, 27.

Colton, C.A., Wilcock, D.M., 2010. Assessing activation states in microglia. CNS Neurol. Disord. Drug Targets 9, 174-191.

Combrinck, M.I., Perry, V.H., Cunningham, C., 2002. Peripheral infection evokes exaggerated sickness behaviour in pre-clinical murine prion disease. Neuroscience $112,7-11$.

Denieffe, S., Kelly, R.J., McDonald, C., Lyons, A., Lynch, M.A., 2013. Classical activation of microglia in CD200-deficient mice is a consequence of blood brain barrier permeability and infiltration of peripheral cells. Brain Behav. Immun. 34, 86-97.

Dungan, L.S., McGuinness, N.C., Boon, L., Lynch, M.A., Mills, K.H., 2014. Innate IFNgamma promotes development of experimental autoimmune encephalomyelitis: a role for NK cells and M1 macrophages. Eur. J. Immunol. 44, 2903-2917.

El Khoury, J., Toft, M., Hickman, S.E., Means, T.K., Terada, K., Geula, C., Luster, A.D., 2007. Ccr2 deficiency impairs microglial accumulation and accelerates progression of Alzheimer-like disease. Nat. Med. 13, 432-438.

Fiala, M., Lin, J., Ringman, J., Kermani-Arab, V., Tsao, G., Patel, A., Lossinsky, A.S., Graves, M.C., Gustavson, A., Sayre, J., Sofroni, E., Suarez, T., Chiappelli, F., Bernard, G., 2005. Ineffective phagocytosis of amyloid-beta by macrophages of Alzheimer's disease patients. J. Alzheimers Dis. 7, 221-232 discussion 255-262.

Gengler, S., Hamilton, A., Holscher, C., 2010. Synaptic plasticity in the hippocampus of a APP/PS1 mouse model of Alzheimer's disease is impaired in old but not young mice. PLoS One 5, e9764.

Godbout, J.P., Chen, J., Abraham, J., Richwine, A.F., Berg, B.M., Kelley, K.W., Johnson, R.W., 2005. Exaggerated neuroinflammation and sickness behavior in aged mice following activation of the peripheral innate immune system. FASEB J. 19, 1329-1331.

Gordon, S., Martinez, F.O., 2010. Alternative activation of macrophages: mechanism and functions. Immunity 32, 593-604.
Jankowsky, J.L., Slunt, H.H., Gonzales, V., Savonenko, A.V., Wen, J.C., Jenkins, N.A. Copeland, N.G., Younkin, L.H., Lester, H.A., Younkin, S.G., Borchelt, D.R., 2005 Persistent amyloidosis following suppression of Abeta production in a transgenic model of Alzheimer disease. PLoS Med. 2, e355.

Jones, R.S., Minogue, A.M., Connor, T.J., Lynch, M.A., 2013. Amyloid-beta-induced astrocytic phagocytosis is mediated by CD36, CD47 and RAGE. J. Neuroimmune Pharmacol. 8, 301-311.

Kelly, R.J., Minogue, A.M., Lyons, A., Jones, R.S., Browne, T.C., Costello, D.A. Denieffe, S., O'Sullivan, C., Connor, T.J., Lynch, M.A., 2013. Glial activation in A beta PP/PS1 mice is associated with infiltration of IFN gamma-producing cells. J. Alzheimers Dis. 37, 63-75.

Kontzias, A., Laurence, A., Gadina, M., O’Shea, J.J., 2012. Kinase inhibitors in the treatment of immune-mediated disease. F1000 Med. Rep. 4, 5.

Kotenko, S.V., Pestka, S., 2000. Jak-Stat signal transduction pathway through the eyes of cytokine class II receptor complexes. Oncogene 19, 2557-2565.

Liu, Y., Holdbrooks, A.T., De Sarno, P., Rowse, A.L., Yanagisawa, L.L., McFarland, B.C., Harrington, L.E., Raman, C., Sabbaj, S., Benveniste, E.N., Qin, H., 2014. Therapeutic efficacy of suppressing the Jak/STAT pathway in multiple models of experimental autoimmune encephalomyelitis. J. Immunol. 192, 59-72.

Martinez, F.O., Gordon, S., 2014. The M1 and M2 paradigm of macrophage activation: time for reassessment. F1000Prime Rep. 6, 13.

McManus, R.M., Higgins, S.C., Mills, K.H., Lynch, M.A., 2014. Respiratory infection promotes $\mathrm{T}$ cell infiltration and amyloid-beta deposition in APP/PS1 mice Neurobiol. Aging 35, 109-121.

Meda, L., Cassatella, M.A., Szendrei, G.I., Otvos Jr., L., Baron, P., Villalba, M., Ferrari, D. Rossi, F., 1995. Activation of microglial cells by beta-amyloid protein and interferon-gamma. Nature 374, 647-650.

Michelucci, A., Heurtaux, T., Grandbarbe, L., Morga, E., Heuschling, P., 2009. Characterization of the microglial phenotype under specific pro-inflammatory and anti-inflammatory conditions: effects of oligomeric and fibrillar amyloid-beta. J. Neuroimmunol. 210, 3-12.

Minogue, A.M., Jones, R.S., Kelly, R.J., McDonald, C.L., Connor, T.J., Lynch, M.A., 2014 Age-associated dysregulation of microglial activation is coupled with enhanced blood-brain barrier permeability and pathology in APP/PS1 mice. Neurobiol. Aging 35, 1442-1452.

Pardanani, A., 2008. JAK2 inhibitor therapy in myeloproliferative disorders: rationale, preclinical studies and ongoing clinical trials. Leukemia 22, 23-30.

Perry, V.H., Holmes, C., 2014. Microglial priming in neurodegenerative disease. Nat. Rev. Neurol. 10, 217-224.

Rezai-Zadeh, K., Gate, D., Gowing, G., Town, T., 2011. How to get from here to there: macrophage recruitment in Alzheimer's disease. Curr. Alzheimer Res. 8 156-163.

Stein, M., Keshav, S., Harris, N., Gordon, S., 1992. Interleukin 4 potently enhances murine macrophage mannose receptor activity: a marker of alternative immunologic macrophage activation. J. Exp. Med. 176, 287-292.

Town, T., Laouar, Y., Pittenger, C., Mori, T., Szekely, C.A., Tan, J., Duman, R.S. Flavell, R.A., 2008. Blocking TGF-beta-Smad2/3 innate immune signaling mitigates Alzheimer-like pathology. Nat. Med. 14, 681-687.

van Gool, W.A., van de Beek, D., Eikelenboom, P., 2010. Systemic infection and delirium: when cytokines and acetylcholine collide. Lancet 375, 773-775.

Verstovsek, S., Kantarjian, H.M., Estrov, Z., Cortes, J.E., Thomas, D.A., Kadia, T. Pierce, S., Jabbour, E., Borthakur, G., Rumi, E., Pungolino, E., Morra, E. Caramazza, D., Cazzola, M., Passamonti, F., 2012. Long-term outcomes of 107 patients with myelofibrosis receiving JAK1/JAK2 inhibitor ruxolitinib: survival advantage in comparison to matched historical controls. Blood 120,1202-1209. 